\title{
Development Challenges Of Fruit And Vegetable Sector Of Uzbekıstan
}

\author{
Iskandarov Sanjarbek Tursunbekovich \\ Tashkent Institute of Irrigation and Melioration, Uzbekistan
}

doi: 10.19044/esj.2016.v12n4p99 URL:http://dx.doi.org/10.19044/esj.2016.v12n4p99

\begin{abstract}
This article presents development challenges of vegetable and fruit production sector in Uzbekistan. The governmental sector reforms, labour resources, price formation, import and export activities have been the object of the study in this article. The paper reviews several problems with developed support system and further development of fruit and vegetable production in Uzbekistan. The paper is aimed to describe the main problems and challenges and suggest their possible solutions.
\end{abstract}

Keywords:Vegetable and fruit production, labour resources, price formation, import and export activitites

\section{Introduction}

Over the years of independence, many efforts to fundamentally restructure the agricultural sector of the country were conducted. According to the principles for reforms, formulated by the President of the Republic of Uzbekistan, the economic transformations in the agriculture are carried out in phases. The following laws have been passed - "On farming", "On dekhkan farming", "On agricultural cooperatives (shirkats)", the Land Code and others. Apart from that, a number of decrees and orders of the President and the Government of the Republic of Uzbekistan were adopted for the development of the agricultural sector as a whole and its individual sectors. In the Presidential Decree "On major directions for deepening of the reforms in agriculture" from March 24, 2003, farming has been identified as a foreground form of economic entity. (www.lex.uz, 2013)

The agrarian reform has led to significant positive changes in the agricultural sector and the production growth. A diversification of the agricultural crops was carried out. Gradual reduction in areas of cotton plant under crops and accommodation in these areas of cereals, vegetables, melons and gourds, potatoes and fodder crops provided an opportunity to prevent 
shortages and higher prices for food products during the global financial crisis.

In the course of reforming of economic activity, forms in agricultural production there have been developed two types of farming: farms and dekhkan farms. These two types of farming are managed in different modes. Farmers are concentrated on the implementation of government quotas on cultivation of cotton and wheat production and are provided with supply chains, they occupy $84.3 \%$ of land resources and their proportion in the production of agricultural products amounts to $35.0 \%$. The republic operates more than 66.1 thousand agricultural holdings. They have been granted to rent 5.8 million hectares of agricultural land in total, of which the planting area amounts to 3.1 million hectares. The average size of a farm accounts for 80 hectares.

\section{Analysis of labour resources}

The level of labor resources requirements for the high-yielding cultures is considerably higher compared to that of cotton and wheat. According to the standards, employment of people per 10 hectares of wheat is calculated in 1 person, per 10 hectares of cotton -5.3 persons, whereas for the production of 10 hectares of vegetables, it takes an average of 21,7 persons, including those for tomatoes - 25.0 persons, cabbage - 14.0 persons, onions - 28.0 persons, cucumbers - 18.0 persons, melons and gourds - 15.5 persons, potatoes - 16.1 persons, fruits -7.7 persons, and grapes -12.2 persons

The analysis of labor productivity in the context of specialization agricultural crops allowed us to establish the following:

In vegetable production, for the whole country under the normative employment of 2.17 persons per hectare, the annual requirement for labor resources amounts to 371.1 thousand persons per year with labor productivity of 17.1 tons per person. For comparison: in Andijan region the productivity of labor is 29.5 tons per person, while in the Republic of Karakalpakstan it is 12.0 tons per person (www.stat.uz, 2013).

In this case, there is no intention to contrast the production of highyielding crops with strategic cultures (cotton and wheat); therefore, the increase in the areas of highly profitable cultures should be within reasonable limits and substantiated from the viewpoint of profitability, employment of the population, created added value and increase in foreign exchange revenues generated from the growth of exports.

Support for rural development in this case should be addressed to processing, packaging and storage of agricultural production, which will allow farmers and dekhkan farmers receive the maximum revenues through the sale of production in the most auspicious time. Thus, the development of 
industry infrastructure for processing, drying, sorting, packaging and marketing (including the export of these cultures) contributes to the creation of additional workplaces, increased added value and foreign exchange revenues.

In recent years sown areas under vegetables and melons are increasing. If in 2007, the proportion of vegetables and melons in the acreage structure of agricultural production were respectively, $4.5 \%$ and $1.1 \%$, then, in 2010 this indicator has increased correspondingly by 4.7 and $1.3 \%$. There are potential opportunities to increase the area sown with vegetables and melons, such as reseeding after harvesting of wheat (depending on water availability on the area of 300-350 hectares) and the use of low-productive lands, where the productivity of a cotton is below 2 tons per hectare, and the productivity of wheat is lower than 2.5 tons per hectare, and revenues do not cover the costs. These lands constitute approximately $20 \%$ of the total irrigated area. As a result of climate changes and the increase in population throughout the world in recent years, the demand for horticultural production and other types of food is increasing. Uzbekistan has implemented wideranging measures to increase production for the saturation of the domestic market with the food products.

There is a tendency for the increase of crop productivity, however, in comparison with parameters of developed countries, and potential opportunities of soil and climatic conditions of the regions of the Republic, the progress indicators are low. To increase the amount of fruit and vegetable processing, the special Government Resolution has created "Agro-firms", which are intended to organize the procurement of fruit and vegetable products from farmers and dekhkan farmers, organize the processing and export of production. Their number across the country is currently 267 units.

\section{Market price formation}

Economic relationships between the founders based on contracts for establishing of domestic prices for products and services. The local market of the Republic of Uzbekistan has gone through lots of development process which resulted in creation of competitive environment between domestic and foreign market. In both markets there exist many market participants and Intermediaries which will be deep discussed in the next following part.

For farmers and dekhkan farmers, selling of fruits and vegetables in the domestic market involves the presence of many market intermediaries (speculators), and as a result, the price of goods from producer to consumer has a certain difference - the revenue, which is set by intermediaries. Furthermore, the presence of large number of intermediaries when products are moving from producers to consumers makes it more difficult for producers to access the market. Absence of special vehicles for 
transportation of fruit and vegetable products, as well as no provision of packaging materials is also a sort of a barrier on the way out for farmers and dekhkan farmers to the domestic market.

Prices for fruit and vegetable products in the internal market during the mass crop ripening is drastically reduced, which does not allow producers to compensate for the costs, and in order to support the producers it evidently is necessary to consider the organization of interventional procurement.

The government periodically organizes fairground sales of horticultural products in cities and regional centers, timing it for the holidays. Prices at such fairs are usually set substantially lower than market; therefore producers are reluctant to participate in these fairs. Nevertheless, because of the absence of alternative in product sales, producers are forced to use this sales channel.

Upward trend in prices for fruit and vegetable production is observed in all regions of the Republic. There are large fluctuations in the prices of fruits and vegetables among the regions (1.5 to 3.5 times). All of this requires protecting the domestic market against the expansion of imports of horticultural products. Here, the Government should establish the necessary legal environment for the private sector in order to improve the quality and competitiveness of production, tighten the customs barriers in relation to those products, which are produced by local farmers within reasonable limits, to avoid creating deficiency in the domestic markets.

\section{Development factors of the sector}

Corporation of Farms. Unification of private and dekhkan farms into cooperatives, differing by kinds of cultures and scope of activities, plays an important role at enhancing the effectiveness of production, processing and marketing. It will consolidate the efforts and resources for the development of processing and infrastructure of the industry, dissemination of knowledge about the new technologies, marketing and management, improvement of products quality and their competitiveness.

Exporting Activities. An annual growth of exports of fruit and vegetable products is provided. Therefore, in 2008 the volume of exported vegetables amounted to 126.4 tons (2.4\% of total volume), while in 2010 this indicator made 292.9 thousand tons, or $4.6 \%$ of total production. The share of exports of fruits in 2008 was $6.7 \%$ and in 2010, it was 10.1 percent of the volume of production, whereas grapes were respectively 10.5 and 9.7 percent [5]. From the data it is evident that the bulk of the fruit and vegetables produced are directed for domestic consumption.[2] A small proportion of products are directed for processing and export. Meanwhile, the yield of fruits and vegetables, melons and grapes is largely connected with added 
value creation (processing, prolonged storage, drying and export). However, these factors are not sufficiently used. (Ministry of Agriculture and Water Resources of the Republic of Uzbekistan, 2009)

During recent years, fruit and vegetable production export is increasing in total. In 2006, exports of fruit and vegetable production increased roughly to 373.3 million USD; in 2010, this trend indicated 1.15 billion USD and increased by more than 3 times (www.stat.uz, 2013).

Only small amounts of products are exported to European markets because of the limitations on transportation, associated with the fact that Uzbekistan does not have access to the sea, and because of the considerable distances. Export of fruits and vegetables to the EU countries is also restricted because Uzbekistan still could not comply with the technical regulations of EU standards in relation to food safety or the sanitary control.

Development of export potential of agriculture requires an increase in quality indicators and the development of the system, aimed at ensuring the safety of food; for these purposes, it is necessary to organize the dissemination of knowledge for ensuring a high quality production for the entire cycle of production-processing-marketing

Development of fruit growing processing, including grapes, and drying of these products, as well as the increase in share of exports of fresh, processed and dried production can provide high profitability to producers and hard currency earnings for the country in general. Exports of dried fruits should become one of the important factors in increase of the export potential of horticultural subcomplex of the country, and competitiveness improvement of fruit and grape subcomplex of Uzbekistan. Using the foothills and unsuitable for tillage lands for these crops can provide employment of the foothill areas population, irrigation water saving using the latest in water conservation technologies.

Political Considerations. Policy concerning increasing the production and the use of fruits and vegetables, melons, fruits and grapes should be fundamentally reconsidered and include the following questions: stimulation of dekhkan and private farms to increase the fruit and vegetable production; consideration of the issues of allocating additional land area to producers, especially to dekhkan farmers; improvement of the exporting system of fruit and vegetable production by expansion of the number of private sector entities, participating in the process of export of production; encouragement of producers for the introduction of scientific and technological progress and their involvement in agricultural R \& D; support of the establishment of producers' cooperatives, procurers, processors and marketers.

Importing Activities. An important factor for the effectiveness of fruit and vegetable subcomplex is the use of production capacity of the very early, early, middle and late growing season of vegetables, potatoes and melons, as 
well as the possibility of production of these cultures in greenhouses. Uzbekistan is divided into several zones, by soil and climatic conditions. (Ministry of Agriculture and Water Resources of the Republic of Uzbekistan). Many of fruit and vegetable plants provide high quality crop in certain areas. Historically, there was formed specialization of regions for certain types of crops. The advantageous factor of zonal specialization of fruit and vegetables by zones, placement of fruit and vegetables, melons and grapes contributes to lower production costs, improves the quality and competitiveness of production. Increase in production of ecologically clean horticultural products, the demand for which is constantly growing, must be one of the most promising destinations in horticulture.

It is the effective use of those factors, which promotes expansion of presence opportunities of fruit and vegetable sector of Uzbekistan on international markets, as well as a year-round provision of horticultural products to the population in fresh processed, frozen and dried condition. Exports of fruits, vegetables, melons and grapes are carried out on a contractual basis for freely convertible currency with strict control of their implementation, in accordance with applicable legislation on foreign exchange regulation.

\section{Conclusion}

It is important to develop an institutional mechanism, such as cooperation and integration of agricultural enterprises. Cooperative unions, farmers, dekhkan farmers and agricultural firms have more opportunities together than each farm individually to acquire advanced technological equipment, effectively implement the sale of products and its export, conduct an effective research of both internal and external markets, analyze and forecast customer demand overseas, identify new directions of cooperation, etc.

At the same time, it is necessary to provide the accumulation of funds for support and development of agricultural production (both on a nonrepayable and on a repayable basis). They should be directed at the development of agricultural science and training, support for elite seed production, improvement of soil fertility, subsidies for the production and sales of separate kinds of fruits and vegetables, etc. Funding for these areas is advisable to carry out by attracting international grants or reserve funds formed in accordance with intergovernmental agreements.

\section{References:}

Resolution of the President of the Republic of Uzbekistan "On measures to develop and strengthen the material-technical base of the storage of horticultural products for the period of 2011-2015" from April 7, 2011. 
Decree of the President of the Republic of Uzbekistan "On major directions for deepening of reforms in agriculture" from March 24, 2003.

Decree of the President of the Republic of Uzbekistan №3709 "On measures to deepen economic reforms in the horticulture and viticulture" from January 9, 2006.

Ministry of Agriculture and Water Resources of the Republic of Uzbekistan, 2009 5th edition.

Resolution of the President of the Republic of Uzbekistan "On additional measures to increase food production and saturation of the domestic market» from January 26, 2009.

"Standards of labor and material resources, required for the cultivation of agricultural production" (in Uzbek). (Tashkent 1997, Pages 3-5, and "Technological map on cultivation of agricultural crops for 2006-2010." Part 2, 2005, Tashkent)

UNDP Analytical Note 2 (15), 2010.

The Governmental portal of the Republic of Uzbekistan http://www.gov.uz/uz/business/agriculture/

The State Committee of the Republic of Uzbekistan on Statistics. http://www.stat.uz/

www.lex.uz

www.gov.uz 